\title{
RESOURCES, RESOURCES EVERYWHERE: REVIEWING MALTHUSIANISM AND URBAN ECOLOGY FOR INDIAN CITIES
}

\author{
Megha Agrawal
}

Delhi Public School, R. K. Puram

DOI: 10.46609/IJSSER.2020.v05i06.018 URL: https://doi.org/10.46609/IJSSER.2020.v05i06.018

\begin{abstract}
Urban ecology is emerging as a crucial area for policy development in developing countries such as India. With more population congestion and strain on resources, dire situations have arisen with respect to lack of accessibility to resources, depletion of groundwater and a deterioration of air quality. Urban ecology as a discipline focuses on developing urban spaces in a sustainable fashion, incorporating renewable energy and efficient usage of spaces so as to reduce negative impact on the environment and citizens. The Malthusian model of population and resource growth has long been touted as a key to development policy. However, this paper will argue that in the context of sustainable urbanization of developing countries, there is a need to reconceptualise the Malthusian model away from a population centric approach. The paper will discuss the importance of urban ecology and sustainably infrastructure in India, and pose policy recommendations for better integration of this discipline in policy at the state and national level.
\end{abstract}

Keywords: Resources, Urban ecology, Malthusian model, Development

\section{INTRODUCTION}

Urban ecology is becoming a growing area of policy, especially of concern to developing countries which are experiencing increased urbanization as well as population growth. Unplanned expansion of the city, changing land use, depleting forest cover, increasing rainfall runoff, and depletion of the water table have all been consequences of India's rapid population growth and the increasing exodus of migrants from rural to urban areas (TNN, 2012). Urban ecology as a policy concern will help understand urban systems in the city and mitigate environmental degradation. Correlation between changing land use patterns, green spaces and the role in local climate change and weather patterns form the core of urban ecology (Wankhade and Balakrishnan, 2011). 


\section{International Journal of Social Science and Economic Research}

ISSN: $2455-8834$

Volume: 05, Issue: 06 "June 2020"

Sustainable urbanization is the need of the hour in developing countries with rapid expansion of industrial areas and metropolitan areas. Those working in sustainable urbanization emphasize that people must understand how urban systems function and how and to what extent they impact and are affected by global or regional processes (TNN, 2012). Urban ecology investigates the interrelations between environmental compartments and human activities such as construction, production, housing, and transport (TNN, 2012). It is also an important area of policy to protect the urban environment from harm and how both environmental quality and physical human living conditions may be improved (TNN, 2012).

This paper will further analyze the importance of urban ecology policy in the context of India. The theory of sustainable resource development and infrastructure will be examined in light of the Malthusian model of population growth and linear resource development. The paper will then pose policy recommendations for a better integration of urban ecology policy, the need, and the benefits of the same.

\section{BACKGROUND}

Urban ecology has seen a rising importance in developing countries, because urban centers became the drivers of economic growth in the post-industrial world (Singh, 2014). The economies of scale worked with large populations inviting synergy which has and continues to facilitate the urban growth process (Singh, 2014). Consequently, the twentieth century witnessed a massive urban transition so much so that at the turn of the century, the world urban population crossed the 50\% mark (Singh, 2014). Most of this increase has come from outsourcing manufacturing and production processes to highly populated developing countries such as India and China.

The process of urbanisation involves a complex set of economic, demographic, social, cultural, technological, and environmental processes that result in an increase in the proportion of urban population living in towns and cities, and an increasing density of population within urban settlements (Singh, 2014). Large amounts of natural resources like food, water, clean air, etc. are consumed in the processes supporting this highly dense urban population (Singh, 2014). Simultaneously, the latter in turn becomes a point source of pollution as it consumes and converts natural resources into waste and harmful by-products like sewage, solid waste, toxic gas emissions, etc (Singh, 2014).

The population-resource model as developed by Thomas Malthus has not only survived throughout time, but could be argued to have become even more relevant as the world's population experiences unprecedented growth (Szabo, 2016). With the total population exceeding seven billion, the potential Malthusian risks have never appeared more pertinent 


\section{International Journal of Social Science and Economic Research}

(Szabo, 2016). Thomas Malthus theorized that populations grew in geometric progression and food supply grew in arithmetic progression, concluding that populations will grow faster than the supply of food. This exponential population growth will lead to a shortage of food (Agarwal, 2020). Malthus then argued that because there will be a higher population than the availability of food, many people will die from the shortage of food (Agarwal, 2020). He theorized that this correction would take place in the form of Natural Checks (such as natural disasters, wars and famines) and Preventative Checks (such as methods of population control) (Agarwal, 2020). These checks would lead to the Malthusian catastrophe, which would bring the population level back to a 'sustainable level (Agarwal, 2020).'

However, economists since then have pointed out that Malthus's theories have not played out, due to the key factor of technological advancements. With advancements in technology related to food and resource production, as well as globalization and increase in trade, it has been argued that food production has increased along with the population, and the population itself has not grown to the levels that Malthus predicted especially in Western, developed countries (Agarwal, 2020).

However, experts argue that the theory remains relevant in developing countries due to the enormous growth in population coupled with levels of poverty that do not allow many to access food and resources even if the food supply exists (Szabo, 2016). With the increase of urbanization in these developing countries therefore, population congestion has only increased and is of particular concern more than the developed countries (Szabo, 2016). Therefore, experts emphasize that for developing countries like India, the Malthusian model remains relevant to develop sustainable resource development as well as sustainable infrastructure in cities. Thomas Malthus, proposed the ground breaking carrying capacity concept, based on the idea that our environment can support a limited population given the demands they place on natural resources and systems (Fernandes, 2017).

However, it is also argued that in an era of rapid urbanization coupled with technological advancements resulting from the continuously increasing power of human capital, a populationcentric approach is outdated (Szabo, 2016). Thus, in order to remain relevant, the Malthusian theoretical framework has to be reconceptualised, so as to serve as a useful tool in identifying and tackling the contemporary challenges related to securing people's livelihoods (Szabo, 2016). It needs to take into account the levels of wealth inequality and inequality in access, which is at the heart of urban ecology, along with the effects on the environment.

\section{DISCUSSION}




\section{International Journal of Social Science and Economic Research}

Land has emerged as a contested resource in Indian urban areas, and is closely linked to the dynamics of other natural resources like water and energy (Wankhade and Balakrishnan, 2011). There is a dire need for urban infrastructure and city planning to be more sustainable in India. A prime example has been highlighted in the publication Yamuna River Project: Urban Ecology in New Delhi (Collectiveblog, 2018). In the last 25 years, the city of New Delhi has tripled its population. This rapid increase also comes with deficient infrastructure, apathetic attitudes towards the environment, a growing economic disparity between, and a lack of urban planning equipped to handle growing populations (Collectiveblog, 2018). While the pollution of the Yamuna River may seem to be a solitary case of one river's pollution, it's issues are not unique to this case (Collectiveblog, 2018). The Yamuna River Project can be applied to other developing cities in Asia, Africa, and Latin America, thus changing the lives of people around the world (Collectiveblog, 2018). The Yamuna River Project teaches us that while pollution and neglect of natural resources may seem insurmountable, architects and designers can take measurable steps to alleviate the stress on the environment (Collectiveblog, 2018).

Experts have insisted that ecology should be considered when the local bodies of cities approve constructions which give birth to untamed urbanization (TNN, 2012). Further, sustainability must improve through cost-effective policies and implementation. For example, government subsidies and interventions through incentives would be a cost effective method of motivating states and corporations to ensure sustainable urbanization especially in large area developments such as townships, neighborhoods, educational campuses, hospitals, etc (TNN, 2012; Wankhade and Balakrishnan, 2011). Incentives to develop solar powered heating systems, waste recycling and green architecture have the potential to work (TNN, 2012). In the context, of developing countries like India, researchers have also argued that the scope of urban ecology should be widened (Mukherjee, 2015). A study conducted in Kolkata demonstrates the benefit of incorporating the study of rural/peri-urban and urban linkages and their transforming interactions from political ecology and historical perspectives (Mukherjee, 2015). By shedding light on the mutually interdependent interrelationship between the city and its peri-urban interface and how it has transformed from a mutually reinforcing system to a truncated one, the Kolkata case study strongly emphasizes the need for integrating political ecology and historical frameworks to render urban ecology more inclusive (Mukherjee, 2015).

Sustainable development of urban infrastructure also needs to be interdisciplinary to successfully tackle large developments - socio economics, hydrogeology and watershed development, comprehensive energy resource planning, sustainable mobility systems, etc (TNN, 2012: Wankhade and Balakrishnan, 2011). For example, with respect to sustainable water management in urban areas in India, comprehensive socio-ecological impact studies related to water sourcing should be carried out to compare and evaluate options before locating new urban centres 
International Journal of Social Science and Economic Research

ISSN: 2455-8834

Volume: 05, Issue: 06 "June 2020"

(Wankhade and Balakrishnan, 2011). Policy measures must also be required to ensure that appropriate infrastructure planning precedes the growth of new cities, rather than following the emergence of the cities, causing a delay and often irreversibly damage to the environment, as the Yamuna River case study shows (Wankhade and Balakrishnan, 2011; Collectiveblog, 2018).

In fact, historians have pointed to sustainable urban planning during the time of the Indus Valley Civilization as a useful model to learn from (Fernandes, 2017). Flourishing trade with Central Asia, investment in the arts, advanced infrastructure and an egalitarian social structure with a relatively low wealth concentration impressed historians and scholars (Fernandes, 2017). Urban planning in that era was more visionary than that of the modern day country equivalents, with orange baked brick houses equipped with internal plumbing, a complex drainage and sewerage system, a functioning water supply system and well defined neighborhoods (Fernandes, 2017).

Another consideration in the context of India and other developing countries, is whether the Malthusian consideration of exponential population growth and linear resource growth function just as well during crisis situations, such as the current COVID-19 pandemic. Crisis situations expose inequalities in accessibility, which are not necessarily accounted for in the Malthusian model (Szabo, 2016). Experts have pointed out that poverty and inequality are not a direct consequence of population growth as they exist in different demographic and spatial contexts (Szabo, 2016). Within-urban inequalities, which have arisen as a new developmental challenge, exacerbate traditional inequality causes (e.g. income) and differentials (e.g. rural-urban) (Szabo, 2016).

Therefore, urban ecology policy must also take into account the issues of accessibility, especially in times of crisis, with sustainable housing structures. For example, the COVID-19 pandemic highlighted the unsustainable nature of urban slums as a housing option due to unsanitary conditions, lack of access to water and hygienic sanitation systems, among other concerns (Chimankar, 2016). Therefore, the Malthusian model must be updated to be interdisciplinary, incorporating healthcare and accessibility ad key planks. The government of India is trying to improve the condition of slums through various programmes but investment should be increased for good results. Monitoring of the various slum development programmes is also required so as to get maximum output (Chimankar, 2016).

\section{CONCLUSION}

Urbanization results in a series of both local and far-reaching effects on biodiversity, biogeochemical cycles, hydrology, and climate, among many other stresses (Wankhade and Balakrishnan, 2011). Many of these effects are not fully understood, as urban ecology has only recently emerged as a scientific discipline and much more research remains to be done. Research 


\section{International Journal of Social Science and Economic Research}

ISSN: $2455-8834$

Volume: 05, Issue: 06 "June 2020"

on cities outside the US and Europe remains limited. Observations on the impact of urbanization on biodiversity and species interactions are consistent across many studies but definitive mechanisms have yet to be established. Urban ecology constitutes an important and highly relevant subfield of ecology, and further study must be pursued to more fully understand the effects of human urban areas on the environment.

There is also a need to carry out a review of existing policies and regulations on the various areas that could be connected to urban ecology, especially in India (Wankhade and Balakrishnan, 2011). While there are relevant national policies on water, urban sanitation, energy and urban transport, there are state subjects, and hence one would need to examine these policies at the state level (Wankhade and Balakrishnan, 2011). Planning norms for states should be reviews and there must be mapping of institutions which are responsible for sustainable growth in urban areas (Wankhade and Balakrishnan, 2011). In the absence of adequate monitoring systems for sustainability, civil society groups have often protested and filed public interest litigation. Collaboration of the government with these civil society groups could be a key avenue to gain valuable insight on the development of urban ecology policy (Wankhade and Balakrishnan, 2011).

Urban factors, such as place of residence and urban growth rates, have a significant impact on vital resources, including food (Szabo, 2016). The impact of urbanisation on the availability of food and access to food depends on country-specific human development context, and future policy research in this field must focus on these specific contexts in further detail (Szabo, 2016). International collaboration could be a key arena wherein to develop further holistic policy measures, for cities to develop a complete vision for development and sustainable growth (TNN, 2012). There is a need to build a broad consensus on sustainable development of cities and urban ecology - that is the interaction between people and the environment in urban and residential contexts, including the inter-relationship between natural and artificial flows of energy and natural resources (TNN, 2012).

\section{REFERENCES}

Agarwal, P, (14 January 2020), 'Malthusian Theory of Population', Intelligent Economist, https://www.intelligenteconomist.com/malthusian-theory/

Chimankar, D, (2016), 'Urbanization and Condition of Urban Slums in India', Indonesian Journal of Geography, Vol. 48, No.1, 28-36 
CollectiveBlog, (29 June 2018), 'Yamuna River Project: Urban Ecology in New Delhi, India', Collective Blog, http://www.collectiveblog.net/yamuna-river-project-arquitectura-medio$\underline{\text { ambiente/ }}$

Fernandes, R, (13 June 2017), 'Lessons in sustainability from India's past: Revisiting the ecological roots of sustainability', City Talk: A Blog by ICLEI, https://talkofthecities.iclei.org/lessons-in-sustainability-from-indias-past-revisiting-theecological-roots-of-sustainability/

Mukherjee, J, (2015), 'Beyond the urban: rethinking urban ecology using Kolkata as a case study', International Journal of Urban Sustainable Development, Vol. 7, Issue 2

Singh, G, (5 October 2014), 'Urban Ecology \& Ecosystem Inputs - Need of the Urban Era', Urban Ecology Research and Action Laboratory, http://urbanecology.in/2014/10/05/urban-ecology-inputs-need-of-the-urban-era/

Szabo, S, (2016), 'Urbanisation and Inequalities in a Post-Malthusian Context: Challenges for the Sustainable Development Agenda', Springer Briefs in Population Studies

Times News Network (TNN), (7 October 2012), 'Urban Ecology Policy can make a difference', The Times of India, https://timesofindia.indiatimes.com/city/pune/Urban-ecology-policycan-make-a-difference/articleshow/16705550.cms

Wankhade, K and Balakrishnan K, (2011), 'Land Infrastructure and Ecological Sustainability in Indian cities', Indian Institute for Human Settlements, http://iihs.co.in/knowledgegateway/wp-content/uploads/2017/05/Land-Infrastructure-and-Ecological-Sustainabilityin-Indian-Cities.pdf 